\title{
An analysis of Skukuza climate data
}

\author{
A.C. Kruger, L.B. Makamo and S. Shongwe
}

Kruger, A.C., L.B. Makamo and S. Shongwe. 2002. An analysis of Skukuza climate data. Koedoe 45(1): 1-7. Pretoria. ISSN 0075-6458.

Data from the climate station at Skukuza, which has been open from 1912 to the present, are analysed. This exercise was done to provide the South African Regional Science Initiative (SAFARI-2000) experimental program with long-term climate statistics and trends. Climate parameters analysed are rainfall, temperature, humidity and sunshine. In the case of rainfall and temperature, the data was first tested for homogeneity and in only three out of 36 monthly cases, the data proved not to be homogeneous. No monthly rainfall trends proved to be significant (at the $5 \%$ level), with five months indicating slightly negative trends and seven slightly positive. Only the monthly maximum temperature series for June proved to be non-homogeneous. The June maximum temperature trend and the February, March, May, July and December minimum temperature trends were significantly positive. The annual time series for minimum temperature were also significantly positive. The monthly results were reiterated by the seasonal results, with the winter maximum temperature trend and the autumn and summer minimum temperature trends significantly positive. Ten months showed negative temperature diurnal range trends with only March being significant. All long-term statistics of rainfall, temperature, humidity and sunshine were found to be typical of a savanna type climate in the southern hemisphere, although average monthly sunshine hours were somewhat less than the norm, due to frequent influx of moist air from the Mozambique Channel.

Key words: Skukuza, SAFARI-2000, climate, trends.

A.C. Kruger, Directorate: Climate Systems, South African Weather Service, Private Bag X097, Pretoria, 0001 South Africa (andries@weathersa.co.za); L.B. Makamo and S. Shongwe, Directorate: Climate Systems, South African Weather Service, Private Bag X097, Pretoria, 0001 South Africa.

\section{Introduction}

The South African Regional Science Initiative (SAFARI-2000) experimental program is developed for southern Africa to explore, study and address linkages between landatmosphere processes and the relationship of biogenic, pyrogenic or anthropogenic emissions and the consequences of their deposition to the functioning of biogeophysical and biogeochemical systems (SAFARI-2000 Home Page). One of the SAFARI-2000 sites is about $13 \mathrm{~km}$ WSW of Skukuza in the Mpumalanga province. Many scientists are involved in the project or will use data forthcoming from it. However, climate data from the site itself only has a measuring period of about two years, from 2000 to 2001 . The purpose of this paper is to provide an analysis of the data of the South African Weather Service climate station at Skukuza, entailing the calculations of long-term averages and trends, for the purpose of background data to interpret measurements at the flux measurement site.

\section{General climate characteristics of the}

area

The climate station of Skukuza is situated at $24^{\circ} 59^{\prime} \mathrm{S}, 31^{\circ} 36^{\prime} \mathrm{E}$ at a height of $263 \mathrm{~m}$ above sea level. The area the station is situated in is generally known as the Lowveld and is 
directly east of the eastern escarpment. According to the new climate regions developed by the South African Weather Service, loosely based on the vegetation regions of Low \& Rebelo (1996) and the Köppen climate classification, Skukuza is situated in the Lowveld Bushveld region, which receives moderate summer precipitation (500-700 mm p.a.) with maximum rainfall in January. Warm to hot temperatures are usually experienced and no frost occurs. The humidity is usually fairly high and this makes summer days uncomfortable. Sunshine duration during summer is below average for this typical savanna climate, due to the influx of moist air from the coast and exacerbated by the proximity of the southern African escarpment close by towards the west. This type of climate lends itself to game, cattle and goat farming, subtropical fruit, vegetables and sugarcane through irrigation, and ecotourism.

\section{Analysis of rainfall}

To obtain a general idea of the rainfall climate of Skukuza, trends and long-term statistics are calculated. But before any analyses can be done, the data first have to be checked for overall quality, as inhomogeneities can influence the results significantly, especially in the case of trend calculations.

\section{Homogeneity of rainfall data}

To test for the homogeneity of Skukuza rainfall data, the non-parametric run test described by Thom (1966) was applied to monthly time series for January to December. This test is based on the number of runs (or groups of consecutive data points) above or below the median value of the time series. The results are shown in Table 1 . In the second column the number of runs are shown which should ideally be about half of the total years used in the calculation (in this case about 80 years of data), to accept the time series as homogeneous. The third column shows the results when compared to the lower and upper $10 \%$ significance limits. Two of the months, March and May, showed possible inhomogeneities in their series, with much fewer than the ideal number of runs. This might indicate a possible trend or slippage in the mean. This is however not evident from the trend calculations, of which the results are shown in the following section. Thus, another possible explanation for the inhomogeneity results is that there might be relatively large clusters of consecutive months with rainfall above or below the median value, but not distributed in a way to cause a trend in the data. For March the largest clusters or runs with four or more consecutive values above or below the median are from 1912 to 1919 (below the median), 1929 to 1934 (above the median), 1943 to 1946 and 1962 to 1966 (below the median), 1967 to 1972 (above the median), and 1973 to 1976 and 1982 to 1986 (below the median). For May the runs are 1934 to 1937 (above the median), 1943 to 1946 (below the median), 1948 to 1951 (above the median), 1962 to 1965 and 1967 to 1970 (below the median), and 1979 to 1983 and 1990 to 1993 (above the median). Except for 1943 to 1946 and 1962 to 1965, none of the above periods are the same for both March and May, thus mostly excluding the probability of artificial biases introduced to the climate series, causing recorded values to be too high or low. Also, no mention is made in the metadata of

Table 1

Results of run test to determine homogeneity of monthly rainfall time series

\begin{tabular}{lcc}
\hline Month & Number of runs & Result \\
\hline Jan & 49 & Homogeneous \\
Feb & 38 & Homogeneous \\
Mar & 34 & Non-homogeneous \\
Apr & 37 & Homogeneous \\
May & 34 & Non-homogeneous \\
Jun & 44 & Homogeneous \\
Jul & 39 & Homogeneous \\
Aug & 37 & Homogeneous \\
Sep & 36 & Homogeneous \\
Oct & 43 & Homogeneous \\
Nov & 38 & Homogeneous \\
Dec & 38 & Homogeneous \\
\hline
\end{tabular}


Monthly rainfall trends (mm p.a.) for the period 1912 to 2001

\begin{tabular}{ccccccccccccc}
\hline Month & Jan & Feb & Mar & Apr & May & Jun & Jul & Aug & Sep & Oct & Nov & Dec \\
\hline Trend & -0.25 & 0.25 & -0.13 & 0.13 & -0.02 & -0.03 & -0.03 & 0.08 & 0.07 & 0.18 & 0.08 & 0.41
\end{tabular}

the station of changes in exposure during, just before or just after the mentioned periods, which lets one come to the conclusion that the above clusters are most possibly natural phenomena, a true reflection of the rainfall received at the station. No attempt was thus made to adjust data in the series before further analysis.

\section{Trends in rainfall}

Table 2 shows the analysis of linear trends in monthly rainfall time series for Skukuza for the period 1912 to 2001 . The month with the highest trend is December with a very small positive value of $0.41 \mathrm{~mm}$ p.a. None of the trends calculated were significant at the $5 \%$ significance level. Trends were also calculated for seasonal rainfall, where summer is defined as the months from December to February, autumn from March to May, winter from June to August and spring from September to November. The results are shown in Table 3. Again, very small trends were detected, the highest being $1.4 \mathrm{~mm}$ p.a. for summer while none of the trends were significant. These results indicate that the long-term rainfall average for Skukuza has remained fairly constant over the past 90 years.

Table 3

Seasonal rainfall trends (mm p.a.) for the period 1912 to 2001

\begin{tabular}{lcccc}
\hline Season & Autumn & Winter & Spring & Summer \\
\hline Trend & -0.07 & 0.07 & 1.1 & 1.4 \\
\hline
\end{tabular}

\section{Long-term rainfall statistics}

Figure 1 and Table 4 show long-term rainfall statistics for the period 1912 to 2001. Similar statistics is supplied by Scholes et al. (2001), but only for a shorter period, ending in 1999. The analyses reveal a typical summer rainfall climate in the southern hemisphere. From the absolute maximum and minimum monthly rainfall it is clear that the rainfall is highly variable, making the area prone to frequent droughts and floods.

\section{Temperature}

The same approach was followed with temperature analyses as in the case of rainfall. Firstly the data was checked for homogeneity, and after that long-term trends and statistics were calculated.

\section{Homogeneity of temperature data}

As with rainfall, the run test described by Thom (1966) was used to test monthly time series for homogeneity. The total number of years of data is 42 years (1960 to 2001).

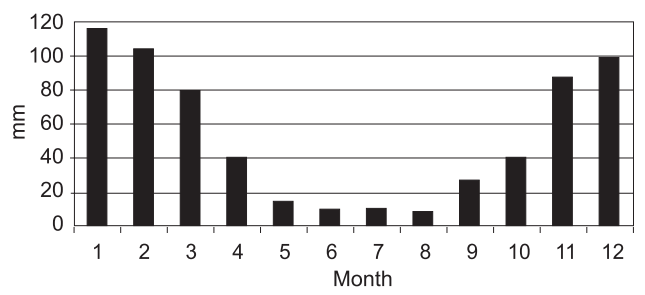

Fig. 1. Average monthly rainfall $(\mathrm{mm})$ for the period 1912 to 2001. 
Table 4

Rainfall statistics (mm) for the period 1912 to 2001

\begin{tabular}{lcccccccccccc}
\hline Statistic & Jan & Feb & Mar & Apr & May & Jun & Jul & Aug & Sep & Oct & Nov & Dec \\
\hline $\begin{array}{c}\text { Absolute } \\
\text { Monthly }\end{array}$ & 835 & 531 & 260 & 222 & 83 & 110 & 132 & 182 & 193 & 231 & 434 & 331 \\
$\begin{array}{l}\text { Maximum } \\
\text { Absolute } \\
\begin{array}{l}\text { Monthly } \\
\text { Minimum }\end{array}\end{array}$ & 8 & 0 & 4 & 0 & 0 & 0 & 0 & 0 & 0 & 0 & 0 & 1 \\
$\begin{array}{l}\text { Maximum } \\
\text { daily } \\
\text { rainfall }\end{array}$ & 103.5 & 119.5 & 86.5 & 71.5 & 56.5 & 40.1 & 75.2 & 40.0 & 85.6 & 44.4 & 67.3 & 99.5 \\
$\begin{array}{c}\text { Average } \\
\text { amount of } \\
\text { rainy days } \\
(>=0.1 \mathrm{~mm})\end{array}$ & 9.8 & 9.6 & 8.8 & 5.7 & 3.0 & 2.1 & 1.8 & 2.3 & 3.3 & 7.0 & 10.6 & 9.8 \\
\hline
\end{tabular}

According to the test, the ideal number of runs should be approximately 21 for a homogeneous data set. The results for the maximum and minimum temperatures are shown in Table 5. The third and last columns show the results of the test when compared to the lower and upper $10 \%$ significance limits. Only the maximum temperature series for July showed possible inhomogeneities in its data series, indicating a high number of short runs in the series. This may in turn indicate a climatic vaccilation of the mean, or relatively short cycles in the series, although this was not verified by graphical analysis.

Trends in maximum and minimum temperature

Table 6 shows the trends of monthly average maximum and minimum temperatures. For the maximum temperature, only July showed

Table 5

Results of run test to determine homogeneity of maximum and minimum temperature time series

\begin{tabular}{lcccc}
\hline Month & $\begin{array}{c}\text { Maximum } \\
\text { temperature } \\
\text { runs }\end{array}$ & $\begin{array}{c}\text { Maximum } \\
\text { temperature } \\
\text { result }\end{array}$ & $\begin{array}{c}\text { Minimum } \\
\text { temperature } \\
\text { runs }\end{array}$ & $\begin{array}{c}\text { Minimum } \\
\text { temperature } \\
\text { result }\end{array}$ \\
\hline Jan & 23 & Homogeneous & 17 & Homogeneous \\
Feb & 19 & Homogeneous & 16 & Homogeneous \\
Mar & 21 & Homogeneous & 24 & Homogeneous \\
Apr & 24 & Homogeneous & 20 & Homogeneous \\
May & 23 & Homogeneous & 24 & Homogeneous \\
Jun & 26 & Non-homogeneous & 19 & Homogeneous \\
Jul & 19 & Homogeneous & 18 & Homogeneous \\
Aug & 23 & Homogeneous & 17 & Homogeneous \\
Sep & 22 & Homogeneous & 22 & Homogeneous \\
Oct & 25 & Homogeneous & 19 & Homogeneous \\
Nov & 23 & Homogeneous & 17 & Homogeneous \\
Dec & 23 & Homogeneous & 25 & Homogeneous \\
\hline
\end{tabular}


Table 6

Monthly and average trend of maximum and minimum temperatures $\left({ }^{\circ} \mathrm{C}\right.$ p.a.) for the period 1960 to 2001 (* indicates significance at the 5\% level)

\begin{tabular}{lcc}
\hline Month & $\begin{array}{c}\text { Maximum } \\
\text { Temperature }\end{array}$ & $\begin{array}{c}\text { Minimum } \\
\text { Temperature }\end{array}$ \\
\hline Jan & -0.020 & 0.007 \\
Feb & -0.005 & $0.029^{*}$ \\
Mar & -0.006 & $0.035^{*}$ \\
Apr & 0.026 & 0.021 \\
May & 0.010 & $0.034^{*}$ \\
Jun & $0.037^{*}$ & 0.011 \\
Jul & 0.008 & $0.041^{*}$ \\
Aug & 0.009 & 0.015 \\
Sep & -0.002 & 0.026 \\
Oct & -0.009 & 0.018 \\
Nov & 0.015 & 0.018 \\
Dec & -0.001 & $0.019^{*}$ \\
\hline Average & 0.005 & $0.024^{*}$ \\
\hline
\end{tabular}

a significant trend at the $5 \%$ level. For the minimum temperature, five of the months showed significantly positive trends, as well as the annual average. These results are consistent with global trends where the minimum temperatures show higher positive trends than the maximum temperature (Easterling et al. 2000), causing the diurnal range in temperature to become progressively smaller. Table 7 shows the seasonal trends for maximum and minimum temperatures. The maximum temperature trend in winter, as well as the minimum temperature trend in autumn and summer, showed significantly positive trends.
Table 7

Seasonal trends of maximum, minimum and average temperatures $\left({ }^{\circ} \mathrm{C}\right.$ p.a.) for the period 1960 to 2001 (* indicates significance at the $5 \%$ level)

\begin{tabular}{lccc}
\hline $\begin{array}{c}\text { Season } \\
\text { Temperature }\end{array}$ & $\begin{array}{c}\text { Maximum } \\
\text { Temperature }\end{array}$ & $\begin{array}{c}\text { Average } \\
\text { Temperature }\end{array}$ \\
\hline Autumn & 0.010 & $0.030^{*}$ & 0.020 \\
Winter & $0.018^{*}$ & 0.029 & $0.024^{*}$ \\
Spring & 0.000 & 0.020 & 0.010 \\
Summer & -0.009 & $0.018^{*}$ & 0.013
\end{tabular}

\section{Trends in diurnal range of temperature}

Table 8 shows the monthly trends in diurnal range of temperature. As can be expected, corresponding with the relative trends in maximum and minimum temperature, the trend is negative for most months, although only the trend for March is significant. For the seasonal trends of diurnal range, as shown in Table 9, all the results were negative. Autumn shows the highest negative trend of $-0.023^{\circ} \mathrm{C}$ per year.

\section{Long-term temperature statistics}

Figure 2 and Table 10 show temperature statistics for the total period of record (1960 to 2001). Similar statistics is supplied by Scholes et al. (2001), but for the period until 1999. Summer temperatures are hot, while during the winter it is mostly warm and pleasant. Minimum temperatures rarely drop below freezing point during winter, but even at this time of the year maximum temperatures can reach levels in the mid-thirties.

Table 8

Trends of monthly diurnal temperature range $\left({ }^{\circ} \mathrm{C}\right.$ p.a.) for the period 1960 to 2001 (*indicates significance at the $5 \%$ level)

\begin{tabular}{ccccccccccccc}
\hline Month & Jan & Feb & Mar & Apr & May & Jun & Jul & Aug & Sep & Oct & Nov & Dec \\
\hline Trend & -0.027 & -0.034 & $-0.041^{*}$ & 0.005 & -0.025 & 0.027 & -0.033 & -0.007 & -0.028 & -0.027 & -0.004 & -0.020
\end{tabular}


Table 9

Trends of seasonal diurnal temperature range $\left({ }^{\circ} \mathrm{C}\right.$ p.a.) for the period 1960 to 2001

\begin{tabular}{lcccc}
\hline Season & Autumn & Winter & Spring & Summer \\
\hline Trend & -0.023 & -0.010 & -0.021 & -0.017
\end{tabular}

\section{Humidity}

Because of frequent influxes of moist air from the east, the humidity should be relatively high. This is reflected in Table 11. The average monthly humidity at 14:00 SAST, which is usually the driest time of the day, ranges from a maximum of $54 \%$ for February to a minimum of $38 \%$ for June and August.

\section{Sunshine}

Average sunshine data for 1960 to 2001 is shown in Table 12. One can see that, although daylight hours in summer is much longer than in winter, the sunshine hours show the opposite, indicating cloudier weather during summer. This region actually receives markedly less sunshine than the

Table 10

Long-term temperature statistics $\left({ }^{\circ} \mathrm{C}\right)$ for the period 1960 to 2001

\begin{tabular}{lcccccccccccc}
\hline Month & Jan & Feb & Mar & Apr & May & Jun & Jul & Aug & Sep & Oct & Nov & Dec \\
\hline $\begin{array}{l}\text { Absolute } \\
\text { minimum }\end{array}$ & 11.3 & 10.0 & 7.6 & 5.6 & 0.8 & -4.4 & -3.8 & -4.2 & 1.3 & 6.4 & 9.9 & 2.0 \\
$\begin{array}{l}\text { Absolute } \\
\text { maximum }\end{array}$ & 43.0 & 45.6 & 42.0 & 41.3 & 39.2 & 35.3 & 36.4 & 38.0 & 42.6 & 43.6 & 42.8 & 42.4 \\
\hline
\end{tabular}

Table 11

Relative humidity (\%) at 14:00 SAST for the period 1978 to 2001

\begin{tabular}{lcccccccccccc}
\hline Month & Jan & Feb & Mar & Apr & May & Jun & Jul & Aug & Sep & Oct & Nov & Dec \\
\hline Average & 53 & 54 & 53 & 48 & 43 & 38 & 39 & 38 & 41 & 45 & 52 & 51 \\
$\begin{array}{l}\text { Lowest } \\
\text { monthly }\end{array}$ & 39 & 37 & 40 & 35 & 30 & 29 & 28 & 30 & 33 & 36 & 39 & 36 \\
$\begin{array}{l}\text { Highest } \\
\text { monthly }\end{array}$ & 66 & 77 & 67 & 57 & 64 & 57 & 58 & 60 & 57 & 56 & 84 & 62 \\
\hline
\end{tabular}

Table 12

Monthly sunshine data (hours) for the period 1960 to 2001

\begin{tabular}{lcccccccccccc}
\hline Month & Jan & Feb & Mar & Apr & May & Jun & Jul & Aug & Sep & Oct & Nov & Dec \\
\hline $\begin{array}{l}\text { Total } \\
\text { average }\end{array}$ & 7.3 & 7.3 & 7.2 & 7.5 & 8.0 & 8.1 & 8.1 & 8.1 & 7.5 & 6.7 & 6.2 & 7.0 \\
$\begin{array}{l}\text { Lowest } \\
\text { average }\end{array}$ & 4.8 & 5.2 & 4.4 & 5.4 & 6.4 & 6.7 & 6.4 & 5.8 & 5.5 & 5.0 & 4.2 & 4.8 \\
$\begin{array}{l}\text { Highest } \\
\text { average }\end{array}$ & 9.1 & 9.6 & 9.3 & 9.4 & 9.4 & 9.4 & 9.6 & 9.5 & 9.3 & 8.5 & 7.8 & 10.8 \\
\hline
\end{tabular}






Fig. 2. Average monthly maximum and minimum temperature $\left({ }^{\circ} \mathrm{C}\right)$ for the period 1960 to 2001 .

norm for savanna regions, the reason being the frequent influx of moist air from the east, with its accompanying fog and cloud.

\section{Discussion and conclusions}

The motivation for this paper is to supply researchers, and other interested parties involved in the SAFARI-2000 project, sufficient long-term background data to serve as a baseline for comparison to future observations at the flux measurement site close by.

Meta data and homogeneity tests suggest that the data is generally of a high quality, suitable for trend analyses. The average rainfall (monthly and seasonal) stayed fairly constant during the previous century. How- ever, there has been a marked increase in minimum temperature since the 1960 s, especially during the summer and autumn months. This result corresponds to the average global trend (Easterling et al. 2000), and can also be considered a true reflection of temperature trends in the area, since no meaningful urbanisation or increased pollution has taken place since the starting point of the time series.

Long-term rainfall and temperature statistics indicate a highly variable climate, typical of the African savanna.

\section{References}

EAsterling D.R., T.R. Karl, K.P. Gallo, D.A. Robinson, K.E. Trenberth \& A. DAI. 2000. Observed climate variability and change of relevance to the biosphere. Journal of Geophysical Research 105: 20101-20114.

Low, A.B. \& A.G. Rebelo (eds.). 1996. Vegetation of South Africa, Lesotho and Swaziland. Pretoria: Department of Environmental Affairs and Tourism.

Scholes, R.J., N. Gureja, M. Giannecchinni, D. Dovie, B. Wilson, N. Davidson, K. Piggott, C. Mcloughlin, K. van der Velde, A. Freeman, S. Bradley, R. Smart \& S. Ndala. 2001. The environment and vegetation of the flux measurement site near Skukuza, Kruger National Park. Koedoe 44(1): 73-83.

SAFARI-2000 WWW Home Page. 2002. Virginia State University. Virginia. U.S.A. (http:// safari.gecp.virginia.edu/)

Тном, H.C.S. 1966. Some methods of climatological analysis. Geneva, Switzerland: World Meteorological Organization. (WMO Technical Note; no. 81.) 
